\title{
Predictive Factors of Spiritual Quality of Life during the COVID-19 Pandemic: A Multivariate Analysis
}

\author{
Jacques Cherblanc ${ }^{1}$ D . Christiane Bergeron-Leclerc ${ }^{2}$. \\ Danielle Maltais ${ }^{2}$. Susan Cadell ${ }^{3}$. Geneviève Gauthier ${ }^{4}$. Oscar Labra ${ }^{5}$. \\ Claudiane Ouellet-Plamondon ${ }^{6}$
}

Accepted: 9 March 2021 / Published online: 23 March 2021

(c) The Author(s), under exclusive licence to Springer Science+Business Media, LLC, part of Springer Nature 2021

\begin{abstract}
COVID-19 has led to the implementation of various social and sanitary measures, impacting populations' quality of life. Aims: Documenting the spiritual quality of life (SQoL) of university employees and students in Quebec, Canada. A survey of 2,202 employees and students was conducted using health measurement tools, including the short version of the WHOQoL-SRPB. We ran a multiple linear regression to determine which variables promote the SQoL. SQoL was very low (2.92/5). Positive mental health, religion, and age are the main predictors of the SQoL. Some dimensions of spirituality contribute more than others to the respondents' quality of life and health during the COVID-19 pandemic.
\end{abstract}

Keywords Spiritual quality of life · COVID-19 - Predictors · University Students and Employees · Quebec · SRPB

Jacques Cherblanc

jcherbla@uqac.ca

1 Humanities and Social Sciences Department, Université du Québec À Chicoutimi, UQAC, 555 Boulevard de l'Université, Chicoutimi, QC G7H 2B1, Saguenay, QC 1-418-545-5011 (5339), Canada

2 Humanities and Social Sciences Department, Université du Québec À Chicoutimi, Saguenay, QC, Canada

3 School of Social Work, Renison University College, University of Waterloo, Waterloo, Canada

4 Laboratoire D'Expertise Et de Recherche en Anthropologie Rituelle Et Symbolique (Laboratory of Expertise and Research in Ritual and Symbolic Anthropology), Université du Québec À Chicoutimi, Saguenay, QC, Canada

5 Teaching and Research Unit in Human and Social Development Sciences, Université du Québec en Abitibi-Témiscamingue, Rouyn-Noranda, QC, Canada

6 École de Technologie Supérieure, Montreal, QC, Canada 


\section{Introduction}

The coronavirus 2019 disease (COVID-19), caused by the SARS-CoV-2 pathogen, has led to the implementation of various novel social and sanitary measures in a number of countries around the world. We are now beginning to see the impact of these actions, including the lockdown of a large part of the population for several weeks, upon people's quality of life and health (De Serres et al., 2020; DRSPM, 2020; Shevlin et al., 2020). Our research concerns the province of Quebec in Canada, where the first COVID-19 case was reported on February 27, 2020. Community transmission in Quebec was confirmed on April 4, 2020 (INSPQ, 2020). The 10,000-case threshold was reached on April 7, 2020, and cases surpassed 50,000 on May 29, 2020 (INSPQ, 2020). As of December 5,2020 , Quebec had a total of 152,030 confirmed cases of COVID-19 since the beginning of the pandemic (INSPQ, 2020).

The first death officially related to COVID-19 in Quebec occurred on March 18, 2020, and the province crossed the threshold of 5,000 deaths on June 8, 2020. As of December 5, 2020, the number of deaths due to coronavirus in Quebec was 7255 (with 12,613 deaths across Canada) (INSPQ, 2020). In Canada, Quebec is the province with the most coronavirus cases and deaths.

\section{The Context of COVID in Quebec}

In Quebec, lockdown measures were intensified gradually but quite rapidly, starting on March 11, 2020 with the banning gatherings of more than 250 people. The March 12 declaration of a "state of sanitary emergency", (that is still in effect at the time of writing) meant the shutdown of various public spaces such as fitness facilities, theaters, bars and restaurants. Soon after, educational institutions and daycare services were closed (March 16), then all non-essential businesses and services (March 22 and 23), and finally essential businesses and services one day per week (March 29). On March 23, 2020 confinement in the public and private residential long-term care facilities for the elderly was introduced. At same time, compulsory confinement was introduced for the entire population, initially with restrictions on travel between regions and police checkpoints to enforce the ban. Some municipalities, such as Montreal and the surrounding cities, even prohibited the use of public parks (Quebec, 2020).

Gradual re-opening was announced between April 15 and 27, but it was not until May 6, 2020, that public and private residences for seniors would allow visitors in and residents out. The ban on interregional travel was lifted on May 18. Schools and other educational institutions re-opened in September 2020 with stringent sanitary measures (Quebec, 2020). Although, unlike some countries, Quebec did not impose home confinement, the measures put in place had a similar effect to the extent that no public place was accessible; Quebecers were therefore de facto confined to their homes for about a month (more or less from March 
15-April 15, depending on the sector). This survey focuses on overall health as perceived by the respondents during that confinement period.

\section{Quality of Life and Spirituality, Religion and Personal Beliefs}

The World Health Organization defines quality of life as an individual's perception of their position in life in the context of the culture and value systems in which they live and in relation to their goals, expectations, standards and concerns" (WHO, 2012, p. 3). Quality of life includes five domains: Physical health, psychological, social relationship, environment and spirituality, religion and personal beliefs (SRPB). We define health as "the positive assessment a person makes of his or her relative physical, psychological, social and spiritual well-being" (Cherblanc et al., in Bergeron-Leclerc, Morin et al., 2019, p. 273). The spiritual quality of life (SQoL) is therefore one of the dimensions considered in health assessment. The WHOQoLSRPB (Group, 2006) is one tool used to study of this phenomenon in a large number of cultures. There are different versions of the WHOQoL-SRPB (Group, 2006), and the WHOQoL-SRPB does have a number of limitations as noted later; however, it also has pertinent strengths (refer below and "Limitations"). For the purpose of this study, we used the approved version in French (Mandhouj et al., 2012) comprising 32 items.

A systematic search in major databases (PubMed, PsychInfo and MedLine) referenced 36 scientific publications reporting the use of the WHOQoL-SRPB. Among these, there were two types of studies: those concerning the role of SRPB in people dealing with illness, trauma or an epidemic and those relating to the SQoL of nonspecific populations. In this second category, we find seven publications concerning academic populations, mainly students (Chai et al., 2012et al., 2012; Hsien-Chuan Hsu et al., 2009; Krägeloh et al., 2015; Krageloh et al. 2015; Lopez et al., 2014; Younis et al., 2012), 10 focusing on unspecified populations (Catré et al., 2019; Chan et al., 2017; Group, 2006; Hammer et al., 2020; Kate et al., 2014; O'Connell \& Skevington, 2005; Skevington \& Böhnke, 2018; Skevington et al., 2013, 2018; Zimpel et al., 2019) and two studies with French participants (Mandhouj et al., 2012, 2014). Overall, these studies show significant differences between respondents for some variables. For example, being female is associated with higher scores on the Connection $(p<0.01)$, Awe $(p<0.01)$ and Faith $(p<0.01)$ dimensions (Group, 2006). Age also appears to play an important role inasmuch as respondents under 45 years of age have lower scores than older individuals for the Connection $(p<0.001)$, Wholeness $(p<0.001)$, Strength $(p<0.001)$, Peace $(p<0.001)$, Hope $(p<0.01)$ and Faith $(p<0.001)$ dimensions (Group, 2006). In addition, respondents with negative perceptions of their health most often have significantly lower scores $(p<0.001)$ than respondents who consider themselves healthy on most scale dimensions (Meaning, Wholeness, Peace, Hope and Faith) (Group, 2006). However, SRPB scores of people with illness can vary significantly over time and independently of other QoL dimensions (Bakiono et al., 2015); in fact, there seems to be a dissociation between the SQoL and other dimensions such as physical health for example (Camargos et al., 2015). To our knowledge, there are no studies on the relationship 
between the SQoL and a pandemic such as COVID-19. However, using the instrument with people with HIV has shown that SRPB can contribute to increasing the perceived overall quality of life of patients (Bakiono et al., 2015). In addition, for people suffering from mental health problems (stress, anxiety) or even serious mental disorders (in particular schizophrenia), SRPB appears to contribute to improving adaptation and lessening certain disabling symptoms (Das et al., 2018; Shah et al., 2011).

Considering oneself as a religious person is also significantly correlated with a higher SRPB score for almost all scale dimensions (Krageloh et al., 2015; O'Connell \& Skevington, 2010; Panzini et al., 2011). Similarly, in less secular countries, the scale scores are quite high: for example, Portugal (4.16, SD: 0.79) (Catré et al., 2019), Jordan (3.45, SD: 0.7) (Younis et al., 2012) and, to a lesser extent, India (3.32, SD: 0.92) (Kate et al., 2014). Conversely, in more secular countries, scores are much lower. This is the case in China (3.15, SD: 0.64) (Chan et al., 2017), England (3.12, SD: 1.02) (Skevington et al., 2018) and France (3.03, SD: 0.78) (Mandhouj et al., 2014). Moreover, having a university education seems to be negatively related to the SRPB score, but in a very limited and insignificant way (Group, 2006; Panzini et al., 2011).

\section{Religion and Spirituality in Quebec}

Since the 1960s, Quebec has been characterized by a rapid and profound process of secularization that has affected both public institutions and individual attitudes and behaviours (Zubrzycki, 2016). Thus, many French-speaking Quebecers have "left religion" (Gauchet, 2005). While declaring themselves to be overwhelmingly Catholic (74.7\% in 2011), Quebecers are less and less religiously active and more so than other Canadians (Clark, 2003; Zubrzycki, 2016). At the same time, however, immigration has led to an increase in religious diversity leading to increased tensions regarding the place and role of religion in the public space (Vaillancourt \& Campos, 2011). Currently, the Quebec government is attempting to enact a law that seems very popular in Quebec (Leger, 2019) to ban the wearing of religious symbols by all state officials in the exercise of their functions (Bilefsky, 2020). Overall, Quebec is thus characterized today by a very republican secularism, that is to say, one that restricts manifestations of religious beliefs or practices (Milot, 2009).

In such contexts, which require profound and numerous adaptations, it is known that religion and spirituality can play a protective role in all dimensions of health (Alten et al., 2019). However, some cultures have "come out of religion" (Gauchet, 2005) in that religion no longer plays the significant role that it continues to occupy elsewhere. In contrast, many sociologists and anthropologists have argued that "homo religiosus" survives, and that in many so-called secularized cultures there is more a "displacement of the sacred" than a "disenchantment of the world". Menard puts it well:

We can mention the theory of the "invisible religion" of Thomas Luckmann (1967), the "civil religion" of Robert N. Bellah (1970), the notion of "secular religion" already put forward by Raymond Aron (about communism and 
Nazism) and developed by Jean-Pierre Sironneau (1982) and Albert Piette (1993), the "implicit religion" of Edward I. Bailey (1997), the theory of "diffuse religion" by Jean Baubérot (1983), the theme of the "return of the sacred" by Daniel Bell (1977), the "theology for atheists" by Franco Ferrarotti (1984), as well as the study of "profane" rites illustrated notably by the work of Claude Rivière (1995). One thinks especially of the enlightening distinctions of Roger Bastide (1978, p. 65-69)[...]: "The "religious" moves, more than it disappears, with the new cults born of the secularization (...), with their ecstatic rites or ceremonial practices (...). The religious are not always in what are called religions; and, conversely, religions are often shrinkages, institutions of defence against the religious, or even mere sentimental appendages of pure moralism (...)". (Ménard, 2001, 240 [our translation])

Thus, in secularized societies as well as religious ones, people believe in something, have ritual and symbolic practices related to experiences of the sacred, while not necessarily belonging to a religion or even calling it spirituality. We wanted to find out through an empirical study whether these beliefs, whether they are called religious, spiritual or personal, could play a protective role against the risk factors associated with the COVID-19 pandemic, especially during the most intense times of containment and major social and health restrictions.

This study sought to assess the role played by the SQoL during the lockdown implemented in the context of the first wave of COVID-19 in Quebec: how was the SQoL impacted and what dimensions of health did the SQoL influence?

\section{Method}

\section{Procedure}

This article presents cross-sectional data, which is part of a longitudinal study, that was gathered between April 24 and June 5, 2020. The data were collected via an online survey on the LimeSurvey platform, from a non-randomized sample of all students and employees of the ten institutions of the Réseau des Universités du Québec (RUQ). Participation was voluntary; written consent was obtained before participation. All survey participants were entered in a draw to win one of twenty \$50 gift cards. Ethics approval for the project (project \#2020-491) was awarded by the Research Ethics Committee of Université du Québec à Chicoutimi (CERUQAC). A total of 2754 people participated in the data collection. Of these, 2202 completed the entire WHOQoL-SRPB (79.9\%).

\section{Measures}

The questionnaire included 149 questions divided into 11 sections: university affiliation and experience, general socio-demographic characteristics, socio-professional experience, relationship health, family health, physical and mental health problems, lifestyle, stress management related to the coronavirus crisis, social health, positive 
mental health, and finally spiritual health. The average time for completion of the survey was $32.3 \mathrm{~min}$. The questionnaire included the following four scales, which were considered in this study because they were correlated with the SQoL.

\section{WHOQOL-SRPB}

To measure SQoL, we used the WHOQoL-SRPB (Group, 2006), translated and validated in French (Mandhouj et al., 2012). This scale, which measures the SQoL, includes 32 items in eight dimensions: Connectedness to a spiritual being or force; Meaning of life; Awe; Wholeness and integration; Spiritual strength; Inner peace; Hope and optimism; Faith. Each dimension is composed of four questions that are given equal weight within each dimension. The mean final facet and global scores can range from 1 to 5; the higher the score, the better the individual's QoL. In this study, very good internal consistency reliability was found for SRPB $(\alpha=0.96)$ and for the SRPB domains ( $\alpha$ between 0.86 and 0.99 for the eight subscales).

The choice of the WHOQoL-SRPB was made after an in-depth search for available and validated tools to measure spirituality. The aim was to find a tool for measuring well-being, health, or the quality of spiritual life that is adapted to a largely secularized culture, but in which religion still occupies an important place. Thus, the wording of the questions and the breadth of the dimensions covered by the questionnaire seemed relevant in assessing the role played by beliefs (whether religious, spiritual, or more personal) on well-being. According to Fleck and Skevington (2007: 69), this measurement tool "does not tie spirituality to religion in QOL research observing that those with agnostic or atheist views may also have a rich spiritual life".

We recognize, however, that what constitutes a strength of this tool is also considered its main weakness. The WHOQoL-SRPB has been criticized for measuring too many different concepts: psychological aspects (such as hope and optimism), religious (faith and connection to a supernatural force or being), and even social or even political (materialistic ideologies such as Marxism that can give meaning to life, optimism and hope for a better world to come) (Moreira-Almeida \& Koenig, 2006). We agree with the authors of the WHOQoL-SRPB who responded that the tool is deliberately inclusive, and that, indeed, "from a QOL perspective, having a profound belief_-religious or not_could give transcendental meaning to life and to daily activities, working as a coping strategy to deal with human suffering and existential dilemmas" (Fleck \& Skevington, 2007: 68). Furthermore, the fact that some dimensions of the WHoQoL-SRPB are correlated with other dimensions (of both physical and mental health-positive or negative — or religion for example) "does not mean that they represent the same dimension or can be used interchangeably" (Fleck \& Skevington, 2007: 68). Thus, despite the criticisms of this tool and in the desire to verify the extent to which the quality of spiritual life-i.e. spiritual, religious and personal beliefs_-contributes to the respondents' overall health, we chose to use the WHOQoL-SRPB. We return to the limitations of this measurement tool at the end of this article. 


\section{Mental Health Continuum-Short Form (MHC-SF)}

The Mental Health Continuum-Short Form (MHC-SF) (Keyes, 2005) is a measure of emotional (3 items), psychological (6 items) and social well-being (5 items). In this study, we used the French version of the MHC-SF, which includes 14 items, to measure positive mental health. This scale of positive well-being also provides a flourishing mental health indicator based on these three subscales. This scale also provides a flourishing mental health indicator based on these three subscales. Very good internal consistency reliability was found for the MHC-SF $(\alpha=0.93)$ in this study.

\section{Social Provision Scale-10 Items (SPS-10)}

The French version of SPS-10 (Caron, 2013), which includes 10 items, was used in this study to measure social support. This is a shortened version of the Social Provisions Scale (Cutrona \& Russell, 1983) validated in French (Caron, 1996). The scale measures five social needs (Weiss, 1973): attachment, reassurance of worth, reliable alliance and guidance. Good internal consistency reliability was found for the total score $(\alpha=0.93)$ and subscales scores ( $\alpha$ between 0.77 and 0.86 for the eight subscales).

\section{Patient Health Questionnaire-2 Items (PHQ-2)}

The French version of HQP-2 (Kroenke et al., 2003), which includes two items, was used here to measure depression. This tool makes it possible to assess the frequency of incidences of depressed mood and anhedonia over the last two weeks. This short version consists of the first two items of HQP-9. In this study, good internal consistency reliability was found for the total score $(\alpha=0.83)$.

\section{Data analysis}

Statistical analyses were conducted using SPSS (version 27) for descriptive and variance analyses and SAS (version 9.4) for multiple regression analyses. We applied a multiple linear regression model with backward elimination. The goal of this type of analysis is to develop a high-quality predictive model that nevertheless includes a minimum number of dimensions. This type of analysis implies that all independent variables are initially included and then eliminated one at a time until the model includes only significant variables. These analyses were used to determine how variables influence each other; Bonferroni adjustments were systematically made to prevent false correlations. 


\section{Participants}

The target population was made up of members of the university communities that are part of the Universités du Québec (UQ) network. These participants were students $(n=1107 ; 50.3 \%)$, employees $(n=952 ; 43.2 \%)$ or individuals with both student and employee status $(n=143 ; 6.5 \%)$. The sample was predominantly female $(70.5 \%)$ and the average age of respondents was 36.95 years $(n=2169$; SD: 12.64; Min: 18, Max: 82). University employees were support staff $(n=278 ; 23.8 \%)$, professionals $(n=250 ; 21.4 \%)$, professors $(n=242 ; 20.7 \%)$, lecturers $(n=237 ; 20.3 \%)$, research professionals $(n=82 ; 7 \%)$, managers $(n=13 ; 1.1 \%)$, or other $(n=52 ; 4.5 \%)$. The majority of students were enrolled full-time $(n=896 ; 72.4 \%)$ in an undergraduate program $(n=794 ; 63.3 \%)$ in the humanities and social sciences $(n=764 ; 61.9 \%)$. From the sample, $72 \%$ of participants reported having an employment income. The other most frequently mentioned sources of livelihood included the Canadian Emergency Benefit $(n=319 ; 14.5 \%)$, scholarships $(n=266 ; 12.1 \%)$, financial support from family $(n=241 ; 10.9 \%)$, and government loans and grants $(n=236 ; 10.7 \%)$. Among participants, $51.3 \%$ indicated that they did not belong to any religion (e.g. atheist, agnostic, humanist) $(n=1127)$ and $40.8 \%$ identified as Catholic $(n=896)$. Various other religions were mentioned by a very small number of respondents ranging from 0.1 to $2.4 \%$. Table 1 lays out the socio-demographic characteristics of the respondents, as well as the variations in the SRPB score according to these characteristics. We present only those characteristics that are found in the final regression model.

\section{Results}

\section{Overview of the Spiritual Quality of Life}

Results indicate a low SQoL for all respondents (2.92/5) during the COVID-19 lockdown, with a large variation according to the dimensions of the scale (Table 2). We categorise the scores into three sets of dimensions. First, two dimensions appear to contribute very poorly to the participants' quality of life. For example, the scores for Faith (1.93) and Connectedness (1.96) are below 2 ("somewhat") and their medians are as low as 1 ("not at all"), meaning that more than half of the respondents felt that Faith and Connectedness (to a spiritual force or being) was "not at all" a source of well-being during the time period studied. Conversely, the dimensions of the SQoL that appear to be the strongest are Awe (3.75), Meaning of life (3.42) and Hope \& optimism (3.41), with medians at or above 3.5, meaning that respondents felt that these dimensions contributed more than "moderately" (3) or even "a lot" (4) to their quality of life. Between these two sets of dimensions that contribute "little" or, on the contrary, "a lot" to the SQoL, there are three dimensions that contribute "moderately": Spiritual strength (2.62), Wholeness (3.05) and Inner Peace (3.19). The analyses did not show significant differences between respondents according to whether they were students, employees, professors or professionals. 
Table 1 Variations in the SRPB score according to sociodemographic characteristics found in the final regression model

\begin{tabular}{|c|c|c|c|c|}
\hline Characteristics & $\mathrm{N}$ & $\%$ & SRPB & $p$ value* \\
\hline \multicolumn{5}{|l|}{ Age (years) } \\
\hline $15-24$ & 459 & $21.2 \%$ & 2.75 & \multirow[t]{6}{*}{$0.000^{*}$} \\
\hline $25-34$ & 575 & $26.5 \%$ & 2.77 & \\
\hline $35-44$ & 537 & $24.8 \%$ & 2.93 & \\
\hline $45-54$ & 347 & $16.0 \%$ & 3.07 & \\
\hline $55-64$ & 203 & $9.4 \%$ & 3.31 & \\
\hline$\geq 65$ & 48 & $2.2 \%$ & 3.42 & \\
\hline \multicolumn{5}{|l|}{ Gender } \\
\hline Female & 1550 & $70.5 \%$ & 2.94 & \multirow[t]{3}{*}{$0.011 *$} \\
\hline Male & 625 & $28.4 \%$ & 2.86 & \\
\hline Other & 23 & $1.1 \%$ & 2.60 & \\
\hline \multicolumn{5}{|l|}{ Marital status } \\
\hline With partner & 1579 & $72.13 \%$ & 2.92 & \multirow[t]{4}{*}{$0.002 *$} \\
\hline Single & 504 & $23.02 \%$ & 2.85 & \\
\hline Divorced/separated & 104 & $4.75 \%$ & 3.18 & \\
\hline Autre & 2 & $0,09 \%$ & 3,31 & \\
\hline \multicolumn{5}{|l|}{ Native people } \\
\hline Yes & 23 & $1.1 \%$ & 3.16 & \multirow[t]{2}{*}{0.155} \\
\hline No & 2158 & $98.9 \%$ & 2.91 & \\
\hline \multicolumn{5}{|l|}{ Visible minority } \\
\hline Yes & 139 & $6.5 \%$ & 3.60 & \multirow[t]{2}{*}{$0.000 *$} \\
\hline No & 2010 & $93.5 \%$ & 2.87 & \\
\hline \multicolumn{5}{|l|}{ Religious affiliation } \\
\hline Yes & 1075 & $48.8 \%$ & 3.20 & \multirow[t]{2}{*}{$0.000^{*}$} \\
\hline No & 1127 & $51.2 \%$ & 2.64 & \\
\hline \multicolumn{5}{|l|}{ Income } \\
\hline Yes & 1585 & $72.0 \%$ & 2.93 & \multirow[t]{2}{*}{0.088} \\
\hline No & 616 & $28.0 \%$ & 2.87 & \\
\hline \multicolumn{5}{|l|}{ Disability pension } \\
\hline Yes & 3.57 & 3 & 3.57 & \multirow[t]{2}{*}{0.168} \\
\hline No & 2.92 & 2199 & 2.92 & \\
\hline \multicolumn{5}{|l|}{ Financial concerns } \\
\hline None & 1196 & $54.36 \%$ & 2.99 & \multirow[t]{4}{*}{$0.000 *$} \\
\hline A little & 465 & $21.14 \%$ & 2.82 & \\
\hline Moderately & 355 & $16.14 \%$ & 2.84 & \\
\hline A lot & 184 & $8.36 \%$ & 2.86 & \\
\hline \multicolumn{5}{|c|}{ Perceived physical health } \\
\hline $\mathrm{Bad}$ & 71 & $3.2 \%$ & 2.37 & \multirow[t]{5}{*}{$0.000 *$} \\
\hline Passable & 329 & $15.0 \%$ & 2.53 & \\
\hline Good & 866 & $39.4 \%$ & 2.86 & \\
\hline Very good & 693 & $31.5 \%$ & 3.07 & \\
\hline Excellent & 241 & $11.0 \%$ & 3.36 & \\
\hline
\end{tabular}


Table 1 (continued)

\begin{tabular}{lcccc}
\hline Characteristics & $\mathrm{N}$ & $\%$ & $\mathrm{SRPB}$ & $p$ value* \\
\hline Positive mental health & $($ Mean: & 44.33; SD: 14.46) & \\
Languishing & 156 & $7.1 \%$ & 1.99 & $0.000^{*}$ \\
Moderate & 1067 & $48.6 \%$ & 2.63 & \\
Flourishing & 971 & $44.3 \%$ & 3.38 & \\
Depression (Mean: 2,54, SD: 1.97$)$ & & \\
$\leq 2$ & 1163 & $52.98 \%$ & 3.18 & $0.000^{*}$ \\
$\geq 3$ & 1032 & $47.02 \%$ & 2.61 & \\
Social support (Mean: $34,09, \mathrm{SD}: 5.19)$ & & \\
$\leq 29$ & 362 & $16.5 \%$ & 2.49 & $0.000^{*}$ \\
$\geq 30$ & 1826 & $83.5 \%$ & 3.00 & \\
\hline
\end{tabular}

Table 2 Means, medians (and Standard Derivation) for WHOQoL-SRPB facets

\begin{tabular}{llllll}
\hline Variable & Mean & Median & Std dev & Minimum & Maximum \\
\hline Srpb (total) & 2.9159571 & 2.8437500 & 0.8257468 & 1.0312500 & 5.0000000 \\
Connectedness & 1.9589010 & 1.0000000 & 1.2610764 & 1.0000000 & 5.0000000 \\
Meaning of life & 3.4245005 & 3.5000000 & 1.0442582 & 1.0000000 & 5.0000000 \\
Awe & 3.7503406 & 3.7500000 & 0.9350651 & 1.0000000 & 5.0000000 \\
Wholeness & 3.0460945 & 3.0000000 & 0.9982541 & 1.0000000 & 5.0000000 \\
Spiritual strength & 2.6200045 & 2.7500000 & 1.2452274 & 1.0000000 & 5.0000000 \\
Peace & 3.1860808 & 3.2500000 & 1.0063273 & 1.0000000 & 5.0000000 \\
Hope & 3.4079246 & 3.5000000 & 0.9522372 & 1.0000000 & 5.0000000 \\
Faith & 1.9338102 & 1.0000000 & 1.2451250 & 1.0000000 & 5.0000000 \\
\hline
\end{tabular}

Thus, respondents' SQoL during the COVID-19 lockdown appears to be very moderate and actually low when compared to other studies using the WHOQoLSRPB. Overall, the aspects of Connectedness (to a spiritual being or force), Faith, and to a lesser extent Spiritual Strength, seem to contribute particularly weakly to respondents' quality of life, which seems consistent with the current secular culture of Quebec. However, the relative importance of the dimensions of Awe, Meaning of life, and Hope \& optimism show that a certain form of spirituality seems to characterize the respondents and that it contributes to their quality of life. Finally, it should be noted that some groups have a significantly higher quality of spiritual life than others (Table 1). This is particularly true for people belonging to a visible minority, having declared a religious affiliation, declaring themselves to be in excellent physical health, or having a flourishing mental health.

\section{Explanatory Model of Spirituality, Religion and Personal Beliefs}

We also sought to understand how this SRPB well-being can be explained from the perspective of the other dimensions of health that were considered in this study. A 


\section{Scaled Residuals for SRPB}
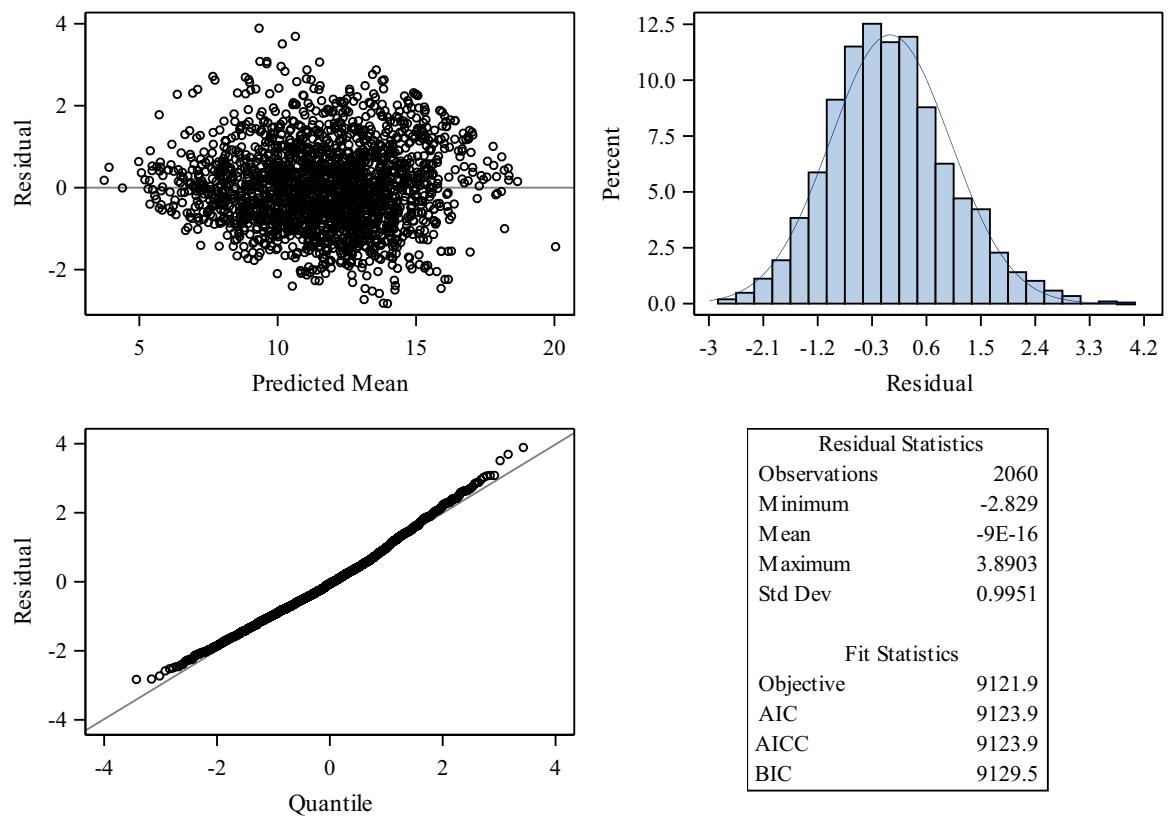

\begin{tabular}{|lr|}
\hline \multicolumn{2}{|c|}{ Residual Statistics } \\
Observations & 2060 \\
Minimum & -2.829 \\
Mean & $-9 \mathrm{E}-16$ \\
Maximum & 3.8903 \\
Std Dev & 0.9951 \\
\multicolumn{2}{|c|}{ Fit Statistics } \\
Objective & \\
AIC & 9121.9 \\
AICC & 9123.9 \\
BIC & 9123.9 \\
\hline \multicolumn{2}{|c}{} \\
\hline
\end{tabular}

Fig. 1 Scaled Residuals for SRPB

linear regression model with backward variable elimination was thus used to identify the variables that explain the SRPB score. The coefficient of determination for the R2 model is 0.56 , which means that the final model, including 12 of the 51 independent variables considered in the initial model, has a very good predictive value. In this model, the assumptions of homogeneity of the variance of the residuals and normality of the residuals are tested (Fig. 1).

\begin{tabular}{lllll}
\hline Type 3 Tests of Fixed Effects & \multicolumn{5}{l}{} \\
\hline Effect & Num DF & Den DF & F Value & $\operatorname{Pr}>$ F \\
\hline Positive mental health (MHC-SF) & 1 & 2039 & 815.40 & $<0.0001$ \\
Religion & 1 & 2039 & 185.50 & $<0.0001$ \\
Racialized & 1 & 2039 & 114.56 & $<0.0001$ \\
Anxiety providing for households & 1 & 2039 & 29.52 & $<0.0001$ \\
Age & 1 & 2039 & 28.82 & $<0.0001$ \\
Perceived physical health & 1 & 2039 & 24.20 & $<0.0001$ \\
Income & 1 & 2039 & 12.56 & 0.0004 \\
Depression (PHQ-2) & 1 & 2039 & 8.72 & 0.0032 \\
Gender & 2 & 2039 & 5.25 & 0.0053 \\
Social support (SPS-10) & 1 & 2039 & 6.02 & 0.0142 \\
Marital status & 8 & 2039 & 5.97 & $<0.0001$ \\
\hline
\end{tabular}


Type 3 Tests of Fixed Effects

\begin{tabular}{lllll}
\hline Effect & Num DF & Den DF & F Value & Pr $>$ F \\
\hline Disability pension & 1 & 2039 & 4.01 & 0.0452 \\
\hline
\end{tabular}

In descending order of importance, the positive mental health score, belonging to a religion, self-identifying as a racialized person, level of concern about being able to provide for one's household, age, perceived physical health, income level, symptoms of depression, gender, social support score, marital status, and receiving disability pensions are the variables that explain the spirituality score.

The positive regression parameter associated with the positive mental health score (Estimate $=0.1292$, Standard Error $=0.004525, t$ Value $=28.56$, $\operatorname{Pr}>|t|<0.0001)$ makes it possible to affirm that the higher an individual's positive mental health score is, the higher his or her spirituality score is. Moreover, the SQoL of individuals belonging to a religion is significantly higher $(\mathrm{LS}-\mathrm{means}=14.6834)$ than that of individuals not belonging to any religion $(\mathrm{LS}-\mathrm{means}=13.2818)(\alpha=0.05)$. Similarly, the SRPB score of racialized individuals is significantly higher $(\mathrm{LS}-\mathrm{means}=15.1013)$ than the spirituality score of non-racialized individuals $(\mathrm{LS}-\mathrm{means}=12.8639)(\alpha=0.05)$. Also, the positive regression parameter associated with age (Estimate $=0.02639$, Standard Error $=0.004916, t$ Value $=5.37, \operatorname{Pr}>|t|<0.0001)$ shows that the older an individual is, the higher his or her SQoL is. Furthermore, the more an individual perceives himself or herself to be in good physical health, the higher his or her spirituality score is (Estimate $=0.02747$, Standard Error $=0.05583, t$ Value $=4.92$, $\operatorname{Pr}>|t|<0.0001)$. Regarding the influence of income, this study shows that individuals with no employment income have a significantly higher score (LSmeans $=14.1941)$ than people with employment income $($ LS-means $=13.7711)$ $(\alpha=0.05)$. For its part, the negative regression parameter associated with the depression score (Estimate $=-0.09144$, Standard Error $=0.03096, t$ Value $=-2.95, \operatorname{Pr}>|t|=0.0032$ ) makes it possible to assert that the higher an individual's depression score is, the lower his or her spirituality score is. The SRPB score of women is also significantly higher $(\mathrm{LS}$-means $=14.2664)$ than that of men $(\mathrm{LS}-$ means $=13.9164)(\alpha=0.05)$. It also appears that the higher an individual's social support score is, the higher their spirituality score is (Estimate $=0.02756$, Standard Error $=0.01123, t$ Value $=-2.45, \operatorname{Pr}>|t|=0.0142$ ). More surprisingly, the spirituality score of divorced individuals is significantly higher (LS-means $=15.0939)$ than the spirituality score of married individuals $($ LS-means $=13$. 9306), individuals in a relationship without cohabitation (LSmeans $=13.8132$ ), individuals who have been living with a spouse for less than twelve months (LS-means $=13.6276)$, and individuals in a common-law relationship $(\mathrm{LS}-\mathrm{means}=13.5223)(\alpha=0.05)$. In addition, the spirituality score of single individuals $(\mathrm{LS}-$ means $=14.2064)$ is significantly higher than the spirituality score of individuals in common-law unions $(\mathrm{LS}-\mathrm{means}=13.5223)(\alpha=0.05)$. Finally, individuals receiving a disability pension have a significantly higher SRPB score $(L S-m e a n s=15.2717)$ than individuals who are not in this situation (12.6935) $(\alpha=0.05)$. 


\section{Discussion}

This study sought to assess the role of the Spiritual Quality of Life in influencing health dimensions during the COVID-19 lockdown in Quebec. Overall, the average scores on the SRPB scale indicate that our Quebec respondents have moderate SQoL, lower than any other known population.

There is evidence that the SQoL influences and is directly influenced by a large number of variables, ranging from gender and mental and physical health to aspects of social support, and even marital status. These influences seem to confirm the cross-cutting nature of spirituality and its links with certain psychological aspects of health (Shah et al., 2011) as well as the protective role that social support plays in individuals' SQoL (Bakiono et al., 2015). These correlations are drawn from samples of people with illnesses and are mostly located in Africa, South America or Asia. Our sample is the first known examination of a healthy North American, French-speaking population.

It is also of note that divorced individuals in our sample, as well as those people receiving a disability pension, demonstrate higher SQoL scores. It is possible that these individuals, as a result of divorce (Mahoney et al., 2008) or the onset of disability (Zhang \& Rusch, 2005), may have tapped into different dimensions of spirituality measured in the WHOQoL-SRPB. These experiences, possibly linked to a painful and difficult or even traumatic event, may have led the individuals concerned to develop their spiritual quality of life, in particular through the adaptive and transformative effects of spirituality (Canda et al., 2019).

Moreover, in line with the scientific literature published on this subject, a significant correlation can be observed between belonging to a religion and a high SQoL score, but it is not the only explanatory factor. The SRPB score would therefore be quite distinct from belonging to a religion alone, even if it is, of course, very strongly related to it. Our study therefore confirms that spirituality, through its dimensions of Awe, Meaning of life and Hope \& optimism, is in equal measure a source of spiritual force that is useful in coping with the stress caused by the pandemic (Del Castillo, 2020). We also note that SRPB scores, in a secular society such as Quebec, are close to those reported in studies conducted in France (Mandhouj et al., 2014), England (Skevington et al., 2013), and China (Chan et al., 2017). Nevertheless, from all the studies we reviewed, the average score of the respondents in this study is the lowest. Indeed, with a score of 2.92 on the SRPB scale, Quebec respondents appear to have a very moderate SQoL, especially when compared to data reported in other published studies. Various explanations seem possible.

First, the respondents' profile may explain a lower score on the SRPB scale. For example, on the one hand, respondents are university students and employees, and therefore relatively educated. However, comparative studies conducted in other countries did not show significant differences in educational characteristics. On the other hand, the vast majority of respondents were born in Quebec and very few seem to be immigrants. This study therefore does not provide information on the SQoL (and overall health) of the more urban and multicultural groups that make up a large and growing portion of the Quebec population. 
Similarly, Quebec is a secular society (Bothwell, 2000) and this may be a factor that explains the lower SRPB score. However, this is also the case for other societies in which the scale has been used (in particular France) and where scores are not as low.

It is therefore possible that the SQoL may have been negatively impacted by the pandemic, even though the other health measurements we've conducted do not show such clear signs of overall poor health (ImpactCovid-19, 2020). Could it be that the SQoL is the first dimension to be affected by the COVID-19 pandemic? It is impossible to answer this question insofar as no pre-pandemic measurement has been done with this population. It would be relevant to compare these results with other measurements done with the same respondents at other times. We plan to do this over the coming year.

\section{Limitations}

As with all research, there are limitations. Some data were missing; the anonymous nature of the survey meant that it was not possible to follow up to clarify. Many recruitment strategies were used; however, the sample is overwhelmingly homogenous, and particularly lacking in the racial diversity that is part of the provincial picture. Some limitations were also of benefit, such as the use of an online survey. This allowed a wide swath of the Quebec population to participate from all parts of the province. At the same time, access to the technology is a limitation. This was mitigated by our target population being university students and employees as they tend to have access to the technologies.

In addition, the WHOQoL-SRPB itself has limitations. While the tool captures spirituality and personal beliefs in and outside of religion affiliations well, there are still some questions regarding its structure and interpretation. Indeed, as MoreiraAlmeida and Koenig (2006) have noted, the conception of the "spiritual" underlying the tool deserves to be clarified. They argued that the inclusion of "personal beliefs" made the instrument too broad and therefore meaningless. Koenig et al., (2012) noted that, if personal beliefs were to be included, they should be made a facet separate from spirituality and religiousness and perhaps integrated into the psychological domain. In addition, Moreira-Almeida and Koenig (2006, p. 844) argued that five facets of the WHOQoL-SRPB (Meaning of life, Awe, Wholeness and integration, Inner peace/serenity/harmony and Hope/optimism) "can be outcomes of religiousness" but "are not, themselves, religiousness or spirituality". Fleck and Skevington (2007) only partially answer these critiques on the concept of spirituality underlying the tool. They explained that the WHOQOL-SRPB's aim is not to evaluate spirituality nor SRPB, but what facets of SRPB appear to be relevant to the respondent's quality of life. For Fleck and Skevington (2007, p. 68) SRPB relates to the sacred, superior being, etc., but also to ideologies, moral and other beliefs: "that is why WHOQOL-SRPB is called WHOQOL-SRPB, not WHOQOLSR or WHOQOL- R".

In order to clarify SRPB, we recommend using the evolutionary concept analysis model, as developed by Rodgers (2000) and Walker and Avant (2004). The model 
differentiates among dimensions of SRPB as antecedents, examples or consequences of spirituality. Thus, in this study, Hope \& optimism, Meaning of Life, and Peace could be considered as consequences of spirituality, while faith could be an antecedent of spirituality. While all of these elements contribute to measuring spiritual quality of life, a more rigorous conceptualization would allow for more precise and perhaps more nuanced analyses.

\section{Conclusion}

We note that even in a secular culture such as Quebec, spirituality has played an active and positive role in the quality of life and health of respondents during the COVID-19 pandemic, but that this phenomenon is attributable to some dimensions more than others. The differences point to a secular spirituality that is more focused on inner and intellectual dimensions than transcendental and emotional dimensions (Comte-Sponville, 2009; Ferry, 2011), which, likewise, are valued in Quebec educational institutions (Cherblanc \& Risdon, 2019). This secular spirituality and its association with better mental and overall health confirms the need for special spiritual support for these population groups, including those who can be described as "spiritual but not religious", as many specialists have argued since the beginning of the pandemic with regard to the population as a whole (Chirico \& Nucera, 2020). Spiritual care workers in health institutions in Quebec, because of their secular posture and their methods and culture of intervention (Cherblanc \& Jobin, 2020a, 2020b) appear to be particularly empowered to enable this necessary tapping into the spiritual, including among caregivers (Koenig, 2020). Their role therefore appears to be decisive in increasing Quebecers' spiritual quality of life, which, according to this study, was particularly low at the beginning of the COVID-19 pandemic.

Funding Centre intersectoriel de santé durable [Intersectoral center for sustainable health], Quebec, Canada. Université du Québec à Chicoutimi, Quebec, Canada. Fédération québécoise des professeures et professeurs d'université [Quebec Federation of University Professors], Quebec, Canada.

Data Availability Due to ethical requirements, the data are not openly available, but it's possible to request at lerars@uqac.ca.

\section{References}

Aten, J. D., Smith, W. R., Davis, E. B., Van Tongeren, D. R., Hook, J. N., Davis, D. E., Shannonhouse, L., DeBlaere, C., Ranter, J., O'Grady, K., \& Hill, P. C. (2019). The psychological study of religion and spirituality in a disaster context: A systematic review. Psychological Trauma: Theory, Research, Practice, and Policy, 11(6), 597-613. https://doi.org/10.1037/tra0000431

Bailey, E. (1997). Implicit Religion in Contemporary Society. Kok Pharos.

Bakiono, F., Guiguimde, P. W., Sanou, M., Ouedraogo, L., \& Robert, A. (2015). Quality of life in persons living with HIV in Burkina Faso: a follow-up over 12 months. BMC Public Health, 15, 1119. https://doi.org/10.1186/s12889-015-2444-4

Bastide, R., (1978) Religion-L'anthropologie religieuse [Religious Anthropology]. Encyclopaedia Universalis. https://www.universalis.fr/encyclopedie/religion-l-anthropologie-religieuse/ 
Baubérot, J. (1983). Religion diffuse et sécularisation [Diffused Religion and Secularization]. Archives de Sciences Sociales des Religions, 56(2), 195-198. https://doi.org/10.3406/assr.1983.2298

Bell, D. (1977). The return of the sacred: The argument on the future of religion. British Journal of Sociology, 28(4), 421-449. https://doi.org/10.2307/3823029

Bellah, R. N. (1970). Beyond belief essays on religion in a post-traditional world. Newyork: Harper and Row.

Bergeron-Leclerc, C., Morin, M.-H., \& Dallaire, B. (2019). La Pratique du Travail Social en Santé Mentale : Apprendre, Comprendre, S'engager [Social Work in Mental Health : Learn, Understand and Engage]. Presses de l'Université du Québec.

Bilefsky, D. (2020). A Quebec ban on religious symbols upends lives and careers. New-York Times. https:/www.nytimes.com/2020/03/07/world/canada/quebec-religious-symbols-ban.html

Bothwell, R. (2000). Canada and quebec: One country two histories. Canada: UBC Press.

Camargos, M. G., Paiva, C. E., Barroso, E. M., Carneseca, E. C., \& Paiva, B. S. (2015). Understanding the differences between oncology patients and oncology health professionals concerning spirituality/religiosity: A cross-sectional study. Medicine (Baltimore), 94(47), e2145. https://doi.org/10. 1097/md.0000000000002145

Canda, E. R., Furman, L. D., \& Canda, H. J. (2019). Spiritual diversity in social work practice: The heart of helping. USA: Oxford University Press.

Caron, J. (1996). L'Échelle de provisions sociales : une validation québécoise [L'Échelle de provisions sociales : Quebec validation of the Social Provisions Scale]. Santé Mentale au Québec, 21(2), 158180. https://doi.org/10.7202/032403ar

Caron, J. (2013). Une validation de la forme abrégée de l'Échelle de provisions sociales : l'ÉPS-10 items. [A validation of the Social Provisions Scale : the SPS-10 items]. Santé Mentale au Québec, 38(1), 297-318. https://doi.org/10.7202/1019198ar

Catré, M. N. C., Ferreira, J. A., Catré, M. C., \& Pereira, M. (2019). Development and application of a short-form questionnaire for assessing spiritual, religious and personal beliefs related to quality of life (WHOQOL-SRPB-BREF) in Portugal. Applied Research in Quality of Life, 16, 241-258. https://doi.org/10.1007/s11482-019-09764-7

Chai, P. P. M., Krägeloh, C. U., Shepherd, D., \& Billington, R. (2012). Stress and quality of life in international and domestic university students: Cultural differences in the use of religious coping. Mental Health, Religion \& Culture, 15(3), 265-277. https://doi.org/10.1080/13674676.2011.571665

Chan, K., Verplanken, B., \& Skevington, S. (2017). Cross cultural application of the WHOQOL-SRPB in the Chinese community with diverse spiritual affiliations. Social Indicators Research, 132(1), 291312. https://doi.org/10.1007/s11205-016-1308-3

Cherblanc, J., \& Jobin, G. (2020a). Théorisation du spirituel à partir de l'analyse de pratiques des Intervenants en soins spirituels au Québec : un modèle original à six dimensions [Theorizing the spiritual from the practice analysis of spiritual care professionals in Quebec: An original six-dimensional model]. Studies in Religion/Sciences Religieuses, 49(2), 290-309. https://doi.org/10.1177/00084 29819858980

Cherblanc, J., \& Jobin, G. (2020b). Soutenir le développement du pouvoir d'agir: Une composante essentielle des soins spirituels au Québec [Sustaining the empowerment of people: An essential component of spiritual care in Quebec]. Studies in Religion/Sciences Religieuses. https://doi.org/10. $1177 / 0008429819893655$

Cherblanc, J., \& Risdon, M.-A. (2019). 'Spiritual life' as the heart of the professionalization process of spiritual and community animators in Quebec, Canada. Journal for the Study of Spirituality, 9(2), 110-124. https://doi.org/10.1080/20440243.2019.1658263

Cherblanc, J., Maltais, D., Freeman, A., Roy, P., \& Bergeron-Leclerc, C. (2019). « Qui veut voyager loin ménage sa monture » ou l'importance de prendre soin de soi pour prendre soin des autres ["He who wants to travel far spares his mount" or the importance of taking care of oneself in order to take care of others]. In C. Bergeron-Leclerc, C., Morin, M. H., Dallaire, B., Cormier, C. La pratique du travail social en santé mentale. Apprendre, comprendre, s'engager [Social work in mental health : Learn, understand and engage] (pp.271-298). PUQ.

Chirico, F., \& Nucera, G. (2020). An italian experience of spirituality from the coronavirus pandemic. Journal of Religion and Health, 59(5), 2193-2195. https://doi.org/10.1007/s10943-020-01036-1

Clark, W. (2003). Pockets of belief: Religious attendance patterns in Canada, Canadian Social Trends. Statistics Canada. (publication n 11-008) https://www.statcan.gc.ca/sites/default/files/6493-eng.pdf. Comte-Sponville, A. (2009). The book of Atheist Spirituality. Bantam: Random House. 
Cutrona, C. E., \& Russell, D. W. (1983). The provisions of social support and adaptation to stress. In W. H. Jones \& D. Pearlman (Eds.), Advance in Personal Relationships (pp. 37-67). Stamford: JAI Press.

Das, S., Punnoose, V. P., Doval, N., \& Nair, V. Y. (2018). Spirituality, religiousness and coping in patients with schizophrenia: A cross sectional study in a tertiary care hospital. Psychiatry Research, 265, 238-243. https://doi.org/10.1016/j.psychres.2018.04.030

De Serres, G., Carazo, S., Lorcy, A., Villeneuve, J., Laliberté, D., Martin, R., Deshaies, P., Bellemare, D., Tissot, F., Adib, G., Denis, G., \& Dionne, M. (2020). Enquête épidémiologique sur les travailleurs de la santé atteints par la COVID-19 au printemps 2020 [Epidemiological survey of healthcare workers affected by COVID-19 in the Spring of 2020]. INSPQ. https://www.inspq. qc.ca/sites/default/files/publications/3061_enquete_epidemiologique_travailleurs_sante_covid_ 19.pdf

Del Castillo, F. A. (2020). Health, spirituality and COVID-19: Themes and insights. Journal of Public Health. https://doi.org/10.1093/pubmed/fdaa185

Direction régionale de santé publique de Montréal [DRSPM]. (2020). Disparités hommes-femmes, Le point sur la santé des Montréalais en période de pandémie [Gender Disparities, Update on the Health of Montrealers in Pandemic Times]. CIUSSS du Centre-Sud-de-l'Île-de-Montréal/DRSP de Montréal. https://santemontreal.qc.ca/population/coronavirus-covid-19/situation-du-coronavirus-covid-19-a-montreal/point-sante/

Gouvernement du Québec [Quebec]. (2020). Measures adopted by orders in council and ministerial orders in the context of the COVID-19 pandemic. https://www.quebec.ca/en/health/healthissues/a-z/2019-coronavirus/measures-orders-in-council-ministerial-orders/

Ferry, L. (2011). Brief history of thought: A philosophical guide to living. NewYork: Harper.

Fleck, M. P., \& Skevington, S. (2007). Explaining the meaning of the WHOQOL-SRPB. Archives of Clinical Psychiatry, 34(1), 146-149. https://doi.org/10.1590/S0101-60832007000700018

Gauchet, M. (2005). Le désenchantement du Monde : Une histoire politique de la religion [The disenchantment of the world: A political history of religion]. Gallimard.

Group, WHOQOL-SRPB (2006). A cross-cultural study of spirituality, religion, and personal beliefs as components of quality of life. Social science and Medicine, 62(6), 1486-1497. https://doi.org/ 10.1016/j.socscimed.2005.08.001

Hammer, J. H., Wade, N. G., \& Cragun, R. T. (2020). Valid assessment of spiritual quality of life with the WHOQOL-SRPB BREF across religious, spiritual, and secular persons: A psychometric study. Psychology of Religion and Spirituality, 12(4), 440-450. https://doi.org/10.1037/rel00 00266

Hsien-Chuan Hsu, P., Krägeloh, C. U., Shepherd, D., \& Billington, R. (2009). Religion/spirituality and quality of life of international tertiary students in New Zealand: An exploratory study. Mental Health, Religion \& Culture, 12(4), 385-399. https://doi.org/10.1080/13674670902752920

ImpactCovid-19. (2020). Les conséquences de la pandémie sur la santé globale des populations universitaires [The impact of the pandemic on the overall health of university populations]. www.uqac.ca/ impactcovid

Institut national de santé publique [INSPQ, Public health expertise and reference centre] (2020). COVID19 (Coronavirus). https://www.inspq.qc.ca/covid-19

Kate, N., Grover, S., Kulhara, P., \& Nehra, R. (2014). Relationship of quality of life with coping and burden in primary caregivers of patients with schizophrenia. International Journal of Social Psychiatry, 60(2), 107-116. https://doi.org/10.1177/0020764012467598

Keyes, C. L. (2005). Mental illness and/or mental health? Investigating axioms of the complete state model of health. Journal of Consulting and Clinical Psychology, 73(3), 539-548. https://doi.org/10. 1037/0022-006x.73.3.539

Koenig, H. G. (2020). Maintaining health and well-being by putting faith into action during the COVID-19 pandemic. Journal of Religion and Health, 59(5), 2205-2214. https://doi.org/10.1007/ s10943-020-01035-2

Koenig, H. G., King, D. E., \& Carson, V. B. (2012). Handbook of Religion and Health (2nd ed.). Oxford: Oxford University Press.

Krägeloh, C. U., Henning, M. A., Billington, R., \& Hawken, S. J. (2015). The relationship between quality of life and spirituality, religiousness, and personal beliefs of medical students. Academic Psychiatry, 39(1), 85-89. https://doi.org/10.1007/s40596-014-0158-z

Krageloh, C. U., Billington, D. R., Henning, M. A., \& Chai, P. P. (2015). Spiritual quality of life and spiritual coping: evidence for a two-factor structure of the WHOQOL spirituality, religiousness, 
and personal beliefs module. Health and Quality of Life Outcomes, 13(26), 1-11. https://doi.org/10. 1186/s12955-015-0212-x

Kroenke, K., Spitzer, R. L., \& Williams, J. B. (2003). the patient health questionnaire-2: Validity of a two-item depression screener. Medical Care, 41(11), 1284-1292. https://doi.org/10.1097/01.MLR. $0000093487.78664 .3 \mathrm{C}$

Léger (2019). Débat sur la laïcité : Rapport de sondage [Debate on laicity: Survey report]. https://leger 360.com/wp-content/uploads/2019/09/11679-221-Rapport-La\%C3\%AFcit\%C3\%A9.pdf

Lopez, V., Fischer, I., Leigh, M. C., Larkin, D., \& Webster, S. (2014). Spirituality, religiosity, and personal beliefs of Australian undergraduate nursing students. Journal of Transcultural Nursing, 25(4), 395-402. https://doi.org/10.1177/1043659614523469

Luckmann, T. (1967). The invisible religion. The problem of religion in modern society. MacMillan.

Mahoney, A., Krumrei, E. J., \& Pargament, K. I. (2008). Broken vows: Divorce as a spiritual trauma and its implications for growth and decline. In S. Joseph \& P. Alex Linley (Eds.), Trauma, recovery, and growth: Positive psychological perspectives on posttraumatic stress (pp. 105-124). Hoboken: John Wiley \& Sons.

Mandhouj, O., Etter, J. F., Courvoisier, D., \& Aubin, H. J. (2012). French-language version of the World Health Organization quality of life spirituality, religiousness and personal beliefs instrument. Health and Quality of Life Outcomes, 10, 39. https://doi.org/10.1186/1477-7525-10-39

Mandhouj, O., Aubin, H. J., Amirouche, A., Perroud, N. A., \& Huguelet, P. (2014). Spirituality and religion among French prisoners: an effective coping resource? International Journal of Offender Therapy and Comparative Criminology, 58(7), 821-834. https://doi.org/10.1177/0306624x13491715

Ménard, G. (2001). Les déplacements du sacré et du religieux [The displacement of the sacred and the religious]. In J.M. Larouche \& G. Ménard (Eds.), L'étude de la religion au Québec : bilan et prospective (pp. 237-250). Presses de l'Université Laval

Milot, M. (2009). L'émergence de la notion de laïcité au Québec. Résistances, polysémie et instrumentalisation [The emergence of the notion of laicity in Quebec. Resistance, polysemy and instrumentalisation]. In P. Eid, P. Bosset, M. Milot et S. Lebel-Grenier (Ed.), Appartenance religieuse, appartenance citoyenne. Un équilibre en tension (pp. 20-38). Presses de l'Université

Moreira-Almeida, A., \& Koenig, H. G. (2006). Retaining the meaning of the words religiousness and spirituality: A commentary on the WHOQOL SRPB group's "a cross-cultural study of spirituality, religion, and personal beliefs as components of quality of life" (62: 6, 2005, 1486-1497). Social Science and Medicine, 63(4), 843-845. https://doi.org/10.1016/j.socscimed.2006.03.001

O'Connell, K. A., \& Skevington, S. M. (2005). The relevance of spirituality, religion and personal beliefs to health-related quality of life: Themes from focus groups in Britain. British Journal of Health Psychology, 10(3), 379-398. https://doi.org/10.1348/135910705X25471

O'Connell, K. A., \& Skevington, S. M. (2010). Spiritual, religious, and personal beliefs are important and distinctive to assessing quality of life in health: A comparison of theoretical models. British Journal of Health Psychology, 15(4), 729-748. https://doi.org/10.1348/135910709X479799

Panzini, R. G., Maganha, C., Rocha, N. S., Bandeira, D. R., \& Fleck, M. P. (2011). Brazilian validation of the quality of life instrument/spirituality, religion and personal beliefs. Revista de Saùde Publica, 45(1), 153-165. https://doi.org/10.1590/s0034-89102011000100018

Piette, A. (1993). Les Religiosités Séculières [Secular Religiosities]. Presses Universitaires de France.

Rivière, C. (1995). Les rites profanes [Secular rituals]. Presses Universitaires de France.

Rodgers, B. L. (2000). Concept analysis. An evolutionary view. In B. L. Rodgers \& K. A. Knafl (Eds.), Concept development in nursing: Foundation, techniques and applications (pp. 77-102). Philadelphia: W-B Saunders Company.

Shah, R., Kulhara, P., Grover, S., Kumar, S., Malhotra, R., \& Tyagi, S. (2011). Contribution of spirituality to quality of life in patients with residual schizophrenia. Psychiatry Research, 190(2-3), 200-205. https://doi.org/10.1016/j.psychres.2011.07.034

Shevlin, M., McBride, O., Murphy, J., Miller, J. G., Hartman, T. K., Levita, L., Mason, L., Martinez, A. P., McKay, R., Stocks, T. V. A., Bennett, K. M., Hyland, P., Karatzias, T., \& Bental, R. P. (2020). Anxiety, depression, traumatic stress, and COVID-19 related anxiety in the UK general population during the COVID-19 pandemic. BJPsych Open, 6(e125), 1-9. https://doi.org/10.1192/bjo.2020.109

Sironneau, J.-P. (1982). Sécularisation et religions séculières [Secularization and secular religions]. Mouton.

Skevington, S. M., \& Böhnke, J. R. (2018). How is subjective well-being related to quality of life? do we need two concepts and both measures? Social Science and Medicine, 206, 22-30. https://doi.org/10. 1016/j.socscimed.2018.04.005 
Skevington, S. M., Gunson, K. S., \& O'Connell, K. A. (2013). Introducing the WHOQOL-SRPB BREF: Developing a short-form instrument for assessing spiritual, religious and personal beliefs within quality of life. Quality of Life Research: An International Journal of Quality of Life Aspects of Treatment, Care \& Rehabilitation, 22(5), 1073-1083. https://doi.org/10.1007/s11136-012-0237-0

Skevington, S. M., Emsley, R., Dehner, S., Walker, I., \& Reynolds, S. E. (2018). Does subjective health affect the association between biodiversity and quality of life? Insights from international data. Applied Research in Quality of Life, 14(6), 1315-1331. https://doi.org/10.1007/s11482-018-9649-5

Vaillancourt, J. G., \& Campos, E. (2011). The regulation of religious diversity in Quebec. Quebec Studies 52:111. https://link.gale.com/apps/doc/A279461673/CPI?u=crepuq_uqac\&sid=CPI\&xid=506eb $7 \mathrm{~b} 2$

Walker, L. O., \& Avant, K. C. (2004). Strategies for theory construction in nursing (4th ed.). New York: Appleton \& Lange.

Weiss, R. S. (1973). Material for a theory of social relationship. In W. Bennis, D. Berlow, E. Schein, \& S.F. Steele (Ed.), Interpersonal Dynamics (pp. 103-111). Dorsey.

World Health Organization [WHO]. 2012. WHOQOL. User manual. Division of mental health and prevention of substance abuse. https://www.who.int/toolkits/whoqol

Younis, M. S., Al-Noaimi, A. S., \& Al-Dabass, M. H. (2012). The effect of religious and spiritual beliefs on the quality of life among university students in Jordan measured by the modified version of (WHOQOL-SRPB) instrument. Arab Journal of Psychiatry, 23(1), 35-40.

Zhang, D., \& Rusch, F. R. (2005). The role of spirituality in living with disabilities. Journal of Religion, Disability \& Health, 9(1), 83-98. https://doi.org/10.1300/J095v09n01_06

Zimpel, R. R., Panzini, R. G., Bandeira, D. R., Fleck, M. P., \& Da Rocha, N. S. (2019). Psychometric properties of the WHOQOL-SRPB BREF, Brazilian Portuguese version. Revista brasileira de psiquiatria (sao Paulo, Brazil), 41(5), 411-418. https://doi.org/10.1590/1516-4446-2018-0083

Zubrzycki, G. (2016). Beheading the saint nationalism, religion and secularism in Quebec. Chicago: University of Chicago Press.

Publisher's Note Springer Nature remains neutral with regard to jurisdictional claims in published maps and institutional affiliations. 